\title{
Mediterranean dietary patterns and risk of type 2 diabetes in the Islamic Republic of Iran
}

\author{
Marjan Ramezan, ${ }^{1}$ Golaleh Asghari, ${ }^{2}$ Parvin Mirmiran, ${ }^{2}$ Zhale Tahmasebinejad ${ }^{2}$ and Fereidoun Azizi ${ }^{3}$
}

${ }^{1}$ Department of Clinical Nutrition and Dietetics, Faculty of Nutrition Sciences and Food Technology, National Nutrition and Food Technology Research Institute, Shahid Beheshti University of Medical Sciences, Tehran, Islamic Republic of Iran. ${ }^{2}$ Nutrition and Endocrine Research Center, Research Institute for Endocrine Sciences, Shahid Beheshti University of Medical Sciences, Tehran, Islamic Republic of Iran ; ${ }^{3}$ Endocrine Research Center, Research Institute for Endocrine Sciences, Shahid Beheshti University of Medical Sciences, Tehran, Islamic Republic of Iran (Correspondence to: Parvin Mirmiran: mirmiran@endocrine.ac.ir).

\begin{abstract}
Background: More than $1 \%$ of urban Iranians aged > 20 years develop type 2 diabetes annually. A major contributing factor is overweight due to energy imbalance and poor quality diet. Even though there are reports on the beneficial effects of some isolated foods on glucose metabolism, researchers are increasingly focusing on dietary patterns versus single foods.

Aims: The aim of this study was to evaluate the association between adherence to a Mediterranean diet and risk of type 2 diabetes.

Methods: The current study was a case-control study nested in the cohort of the Tehran Glucose and Lipid Study. Among participants who met the study criteria, 187 incident cases of diabetes were identified and matched with 374 healthy controls according to sex, age, date of data collection, and previous history of lifestyle intervention.

Results: In the highest Mediterranean Diet Scale (MDS) category there were higher intakes of energy, fibre, glycaemic load, carbohydrate, total fat, and olive oil. However saturated fatty acid and monounsaturated fatty acid intakes decreased in higher MDS categories. The multiple adjusted odds ratios (ORs) for type 2 diabetes among individuals with medium (score 3-4) and high (score 5-8) adherence to MDS were 0.79 (95\% CI:0.38-1.65) and 0.93 (95\% CI:0.44-1.96), respectively, compared to individuals with low adherence (score 0-3).
\end{abstract}

Conclusion: Adherence to the Mediterranean dietary pattern was not associated with type 2 diabetes. Increased rates of type 2 diabetes in the Islamic Republic of Iran might be accounted for by the cultural and traditional differences between the Iranian and the Mediterranean dietary patterns.

Keywords: Mediterranean diet, diabetes, diet quality, Mediterranean Diet Score

Citation: Ramezan M; Asghari G; Mirmiran P; Tahmasebinejad Z; Azizi F. Mediterranean dietary patterns and risk of type 2 diabetes in the Islamic Republic of Iran. East Mediterr Health J. 2019;25(12):896-904. https://doi.org/10.26719/emhj.19.035

Received: 27/07/16; accepted: 26/12/17

Copyright (c) World Health Organization (WHO) 2019. Some rights reserved. This work is available under the CC BY-NC-SA 3.o IGO license (https:// creativecommons.org/licenses/by-nc-sa/3.o/igo).

\section{Introduction}

Type 2 diabetes is a highly prevalent noncommunicable disease at a global level (1). Its prevalence is increasing across the globe, including in the Islamic Republic of Iran (2). The worldwide incidence is projected to rise from 171 million in 2000 to 366 million in 2030, imposing exorbitant costs on health care systems. This diabetes epidemic will continue even if obesity levels remain constant (1). In the Islamic Republic of Iran, more than $1 \%$ of the urban population aged over 20 years develops type 2 diabetes annually (2). Hyperglycaemia caused by diabetes can lead to dysfunction and failure of various organs, specifically nerves, kidneys, eyes, heart and blood vessels (3). The major cause of type 2 diabetes is overweight due to energy imbalance; poor diet quality also plays a role (4). Even though there are reports on the beneficial effects of some isolated foods or food groups on glucose metabolism, currently researchers are increasingly focusing on dietary patterns versus single foods, since there are some interactions between single foods and nutrients that can confound the association between nutrition and the disease (5).
The Mediterranean diet is native to the Mediterranean region, an area with low incidence of chronic diseases and high life expectancy, which has made this dietary pattern important for public health (6).There is evidence that a Mediterranean dietary pattern protects against coronary heart disease (7), and based on the analogy between coronary heart disease and diabetes, this diet has also been postulated as being effective for the prevention and treatment of type 2 diabetes (8). Its protective role could be due to its ability to prevent weight gain and also to it being a source of beneficial components such as polyphenols and monounsaturated fatty acids (MUFAs) $(9,10)$.

Trichopoulou et al. invented a scale for measuring adherence to the Mediterranean diet and named it the Mediterranean Diet Scale (MDS) (11); the diet entails a high consumption of vegetables, fruits and nuts, cereals, legumes and fish. It has a high ratio of MUFAs and saturated fatty acids (SFAs), moderate alcohol use, moderate dairy consumption and low consumption of meat and meat products.

Several studies have investigated the role of adherence 
to a Mediterranean diet on type 2 diabetes risk through a priori dietary scores $(4,10,12-19)$. A recent systematic review of randomized controlled trial and cohort studies showed that greater adherence to a Mediterranean diet measured by a priori scores is associated with a significant reduction in the risk of type 2 diabetes (20). However not all studies assessed Mediterranean diet compliance using a uniform scale, and most were conducted in the United States of America and European countries (20). With respect to cultural variations in dietary habits and possible biological differences in metabolism among different ethnic groups, associations between diet and disease may differ across geographical populations and ethnic groups (19).

To the best of our knowledge, no study has yet carried out research on the associations between a priori-defined dietary quality indices and risk of type 2 diabetes in the Middle East and North Africa (MENA) region. Therefore, our main aim was to evaluate the association between the MDS and risk of type 2 diabetes in a nested casecontrol design study among a healthy adult population in the Islamic Republic of Iran.

\section{Methods}

\section{Design and study population}

This study was run within the framework of the Tehran Lipid and Glucose Study (TLGS), an ongoing urban population-based cohort study aimed at evaluating the risk factors of noncommunicable diseases and their prevention through healthy lifestyles (21). Study participants were 15005 residents (aged 3-75 years) of district No. 13 in Tehran, selected from 3 different health care centres between March 1999 and December 2001. Demographic, clinical, lifestyle and dietary data is collected for the TLGS over 3-year periods. First, a cross-sectional study was conducted from 1999 to 2001, then prospective follow-up surveys, 2 (2002-2005), 3 (2006-2008) and 4 (2009-2011), were performed.

Our study was a nested case-control study in the third and fourth surveys of the TLGS. Our participants were male and female adults $>20$ years for whom we had complete sociodemographic, clinical, lifestyle and dietary data. Cases were participants who were newly diagnosed with diabetes in the third (2006-2008) and fourth (20092011) surveys who had been free of diabetes in previous surveys. American Diabetes Association criteria for case determination were: fasting plasma glucose $\geq 126 \mathrm{mg} /$ $\mathrm{dL}, 2$ hours plasma glucose ( 2 h-PG) after conducting an oral glucose tolerance test (OGTT) $\geq 200 \mathrm{mg} / \mathrm{dL}$, or current therapy for a definite diagnosis of diabetes (3). In total, 641 cases of incident diabetes were identified, of whom we had complete dietary data for 221. Those who were pregnant or lactating $(n=1)$, had over- or under-reported energy intake $(n=17)$, or had a history of cancer or cardiovascular diseases $(n=16)$ were excluded. In all, 187 new cases of diabetes remained for analysis. For each case, 2 controls of the same age, sex and date of data collection ( \pm 6 months gap for data collection), were selected from among the healthy population $(n=$ 374) with the individual matching method. Criteria for control selection were: fasting plasma glucose $<100 \mathrm{mg} /$ $\mathrm{dL}, \mathrm{OGTT}<140 \mathrm{mg} / \mathrm{dL}$ and absence of other exclusion criteria. Since-one third of participants had gone through an educational lifestyle intervention programme, cases were also matched on the basis of intervention. The study protocol was approved by the ethics committee at the Research Institute for Endocrine Sciences of Shahid Beheshti University of Medical Sciences, and all partiipants provided written informed consent.

\section{Dietary assessment}

A semi-quantitative food frequency questionnaire, used to assess dietary intakes during the preceding year, was administered by expert interviewers who had performed nutritional assessment for at least 3-5 years, either in the TLGS or in countrywide food consumption survey projects. The validity and reliability of the questionnaire regarding dietary pattern has been reported in previous studies (22). The food frequency questionnaire consisted of 168 items (22-24) and contained typical foods with standard serving size commonly consumed by Iranians. Participants reported the intake of each food item in a day, week or month in the previous year. The reported frequency was converted to daily consumption for each food item. Portion sizes of consumed foods were then changed to grams using household measures. For measurement of nutrients in foods we used the USDA food composition table (25) and for those items that were absent in that database the Iranian Food composition table was used as an alternative (26).

Based on Trichopoulou et al. (11), we categorized food intakes into 8 major components: vegetables, legumes, fruits and nuts, cereal, fish, meat and poultry, dairy products and ratio of MUFA to SFA. For religious reasons, alcohol consumption is not usual or is probably underreported in the Iranian population, therefore we excluded the alcohol component. We used the sexspecific median of consumption as a cut-off for scoring. For beneficial components, i.e. vegetables, legumes, fruits and nuts, cereal, fish and the ratio of MUFA to SFA, participants scored 1 for being at or above the cutoff and o for being below it. For components anticipated to be detrimental, i.e. meat, poultry and dairy products, participants who had a consumption below the cut-off scored 1, and those whose consumption was at or above the cut-off scored o. Thus, the final MDS scores ranged from o (minimal adherence) to 8 (maximal adherence). The score used by Trichopoulou et al. awarded points for potato intake (11), whereas ours did not. Since the consumption of potato is quite high in our population and it has a high glycaemic index, including potatoes in the vegetable group could lead to a false increase in the scores for this food group. The MDS values of the studied population were then split into 3 categories: low adherence (score 0-2), medium adherence (score 3-4) and high adherence (score 5-8) (11).

We also assessed the glycaemic load for each 
participant: values assigned to individual food items were obtained from the Atkinson table using glucose as the reference (27). Serving size and carbohydrates available in each serving are presented in this table. We calculated the amount of available carbohydrate in each food item consumed by multiplying the available carbohydrate in each serving by the intake of that food item and divided by serving size. The glycaemic load for each item was then calculated according to Atkinson et al. by multiplying its glycaemic index by the available carbohydrate divided by 100 (27). The total glycaemic load for each person was then calculated by adding up the glycaemic load of all products with a carbohydrate content.

\section{Other measurements}

Participants were interviewed by qualified interviewers using pretested questionnaires to gather data on sociodemographics, anthropometrics, family history of diabetes, medical history, and smoking status. This was carried out during the third and fourth surveys of the TLGS, according to which survey the respondent participated in.

Height and weight were measured with light clothes and shoes removed according to the standard protocol, then body mass index (BMI) was calculated. Waist circumference (WC) was measured at the level of the umbilicus over light clothing (21). Blood pressure was also measured using a standardized mercury sphygmomanometer on the right arm while sitting. The mean of 2 measurements was considered the participant's blood pressure. Physical activity during the preceding year was determined using the Modifiable Activity Questionnaire and calculating metabolic equivalent task (MET) minutes per week. The reliability and validity for the Farsi version of the questionnaire has been confirmed previously (28). The MET value of the activity was multiplied by the duration of each of the activities and all MET-minute products were summed to reach an estimate of daily physical activity, indicating energy expenditure per kilogram body weight during an average day. Levels of physical activity were then categorized as light (MET < $600 \mathrm{~min} /$ week), moderate $(\mathrm{MET}=600-1499$ $\mathrm{min} /$ week), and vigorous (MET $\geq 1500 \mathrm{~min} /$ week).

An overnight fasting blood sample was drawn from each participant for biochemical measurements. In addition to measuring fasting plasma glucose, another blood sample was obtained 120 minutes after the ingestion of $82.5 \mathrm{~g}$ glucose monohydrate solution, equivalent to $75 \mathrm{~g}$ hydrous glucose, for the OGTT. Glucose was assayed by an enzymatic colorimetric method (glucose oxidize technique) utilizing glucose kits (Pars Azmun Inc., Tehran). Total cholesterol concentrations were measured with cholesterol esterase and cholesterol oxidase using an enzymatic colorimetric method. The analysis of samples was performed using a Selectra 2 auto-analyser (Vital Scientific, Spankeren) (21).

\section{Definition}

Type 2 diabetes was defined as fasting plasma glucose $\geq 126 \mathrm{mg} / \mathrm{dL}, 2 \mathrm{~h}-\mathrm{PG}$ after OGTT $\geq 200 \mathrm{mg} / \mathrm{dL}$, or receiv- ing current therapy for a definite diagnosis of diabetes, according to the American Diabetes Association criteria (3). Hypertension was determined if systolic blood pressure was $\geq 140 \mathrm{mmHg}$, diastolic blood pressure was $\geq 90$ $\mathrm{mmHg}$, or the person was under current treatment with antihypertensive medications, either at the time of interview or in the previous month, according to the JNC-VIII criteria (29). Hypercholesterolaemia was defined as plasma cholesterol $>200 \mathrm{mg} / \mathrm{dL}$, according to NCEP-ATP III (30). Energy intake reports over $3500 \mathrm{kcal} / \mathrm{day}$ in women or $4200 \mathrm{kcal} /$ day in men were considered over-reporting and energy intake reports under $500 \mathrm{kcal} /$ day in women or $800 \mathrm{kcal} / \mathrm{day}$ in men were considered under-reporting (31).

\section{Statistical analysis}

We matched each case with 2 healthy controls according to age, sex, date of data collection and existence of lifestyle intervention, using an individual matching method. Means and standard deviations, or proportions of potential diabetes risk factors were determined at baseline in cases and controls. The t-test and Chi-squared test were used to compare means and proportions for the case and control groups; $P$ for trend was calculated by assigning the median value for each category of MDS treated as a continuous variable using linear (for continuous variables) or binary logistic (for dichotomous variables) regression. Conditional logistic regression models were used to estimate the OR and the $95 \%$ confidence interval (95\% CI) in each quartile. We used SPSS, version 17.0, and STATA, version 13.0, for statistical analysis. P-values $<0.05$ were considered statistically significant. Model 1 was adjusted for family history of diabetes, BMI, education level, smoking status, physical activity and total energy intake; model 2 was further adjusted for WC, hypercholesterolaemia and hypertension.

\section{Results}

Mean BMI and WC were significantly higher in the case group than the control group (Table 1). Cases were significantly more likely to be hypertensive and hypercholesterolaemic than controls. We compared glycaemic load, total fibre, trans-fatty acids (TFAs), MUFAs, PUFAs between cases and controls. Furthermore, we compared MDS and its components between the 2 groups. After performing the t-test, none of them differed significantly except the MUFA to PUFA ratio (Table 1).

Table 2 presents some demographic and lifestyle variables and some dietary factors. Study participants in the highest MDS category were slightly older compared to the lowest one. Energy, fibre, glycaemic load, carbohydrate, and total fat intake were also higher in the highest MDS category. The proportion of both SFA and MUFA decreased with higher MDS category; however intakes of olive oil shower an upward trend.

The associations between MDS and type 2 diabetes are presented in Table 3. Compared to the lowest, the risk of type 2 diabetes in the highest category of MDS was 


\begin{tabular}{|c|c|c|c|c|c|}
\hline \multirow[t]{2}{*}{ Characteristic } & \multicolumn{2}{|c|}{$\begin{array}{c}\text { Cases } \\
(n=187)\end{array}$} & \multicolumn{2}{|c|}{$\begin{array}{l}\text { Controls } \\
(n=374)\end{array}$} & \multirow[t]{2}{*}{ P-value } \\
\hline & Mean & SD & Mean & SD & \\
\hline Age (years) & 51.0 & 13.0 & 50.8 & 12.7 & 0.871 \\
\hline Body mass index ( $\mathrm{kg} / \mathrm{mz})$ & 30.8 & 5.7 & 28.4 & 4.9 & $<0.001$ \\
\hline Waist circumference $(\mathrm{cm})$ & 101.2 & 12.4 & 94.7 & 11.9 & $<0.001$ \\
\hline Total fibre (g) & 46.5 & 32.5 & 44.0 & 21.6 & 0.343 \\
\hline Glycaemic load & 158.0 & 68.1 & 158.0 & 8.4 & 0.997 \\
\hline TFA (\% of energy) & 0.69 & 0.66 & 0.73 & 0.62 & 0.526 \\
\hline MUFA (\% of energy) & 25.5 & 11.5 & 25.2 & 10.3 & 0.219 \\
\hline PUFA (\% of energy) & 16.1 & 9.8 & 15.3 & 7.0 & 0.061 \\
\hline MDS score & 4.04 & 1.53 & 4.02 & 1.49 & 0.874 \\
\hline Vegetables (g/day) & 312 & 186 & 318 & 184 & 0.535 \\
\hline Legumes (g/day) & 34 & 32 & 36 & 38 & 0.130 \\
\hline Fruits and nuts (g/day) & 423 & 346 & 448 & 376 & 0.531 \\
\hline Cereals (g/day) & 431 & 204 & 415 & 186 & 0.213 \\
\hline Fish (g/day) & 10 & 12 & 11 & 15 & 0.196 \\
\hline Meat and poultry (g/day) & 48 & 35 & 48 & 43 & 0.880 \\
\hline Dairy (g/day) & 399 & 251 & 418 & 257 & 0.658 \\
\hline \multirow[t]{2}{*}{ MUFA to SFA ratio } & 1.1 & 0.29 & 1.0 & 0.25 & 0.013 \\
\hline & \multicolumn{2}{|c|}{$\%$} & \multicolumn{2}{|c|}{$\%$} & \\
\hline Male (\%) & \multicolumn{2}{|c|}{42.8} & \multicolumn{2}{|c|}{42.2} & 0.904 \\
\hline \multicolumn{6}{|l|}{ Smoking (\%) } \\
\hline Non-smoker & \multicolumn{2}{|c|}{81.8} & \multicolumn{2}{|c|}{79.1} & 0.560 \\
\hline Past smoker & \multicolumn{2}{|c|}{$7 \cdot 5$} & \multicolumn{2}{|c|}{7.0} & \\
\hline Smoker & \multicolumn{2}{|c|}{10.7} & \multicolumn{2}{|c|}{13.9} & \\
\hline \multicolumn{6}{|l|}{ Education (\%) } \\
\hline Primary and under & \multicolumn{2}{|c|}{21.9} & \multicolumn{2}{|c|}{24.9} & 0.558 \\
\hline Guidance school & \multicolumn{2}{|c|}{13.9} & \multicolumn{2}{|c|}{15.5} & \\
\hline High school & \multicolumn{2}{|c|}{50.3} & \multicolumn{2}{|c|}{43.9} & \\
\hline University & \multicolumn{2}{|c|}{13.9} & \multicolumn{2}{|c|}{15.8} & \\
\hline Hypertension (\%) & \multicolumn{2}{|c|}{44.9} & \multicolumn{2}{|c|}{29.1} & $<0.001$ \\
\hline Hypercholesterolaemia (\%) & \multicolumn{2}{|c|}{57.2} & \multicolumn{2}{|c|}{42.8} & 0.002 \\
\hline
\end{tabular}

$S D=$ standard deviation; TFA = trans-fatty acid; MUFA = monounsaturated fatty acid; PUFA = polyunsaturated fatty acid; MDS = Mediterranean Diet Scale; SFA = saturated fatty acid.

0.95 (95\% CI: 0.56, 1.61) in the crude model. When adjusted for known confounding factors including family history of diabetes, BMI, physical activity, education level, smoking status, and total energy intake (Model 1), the OR was lower but it was still not statistically significant (OR: 0.87, 95\% CI: 0.43, 1.75). Further adjustment for WC, hypercholesterolaemia, and hypertension attenuated the association (OR: 0.93, 95\% CI: 0.44, 1.96). None of the models showed significant association between MDS adherence and the risk of type 2 diabetes.

In a further analysis, we entered all 8 components of the score in the logistic regression separately. None of the components showed a significant relationship with diabetes risk except for the MUFA to SFA ratio, which was associated with a 2 -fold increase in diabetes risk only in the crude model (data not shown).

\section{Discussion}

In this case-control study nested in a large cohort, adherence to a Mediterranean diet, assessed by an a priori dietary score was not associated with type 2 diabetes in adult men and women of an urban Iranian population.

Our results are in line with 2 previous prospective studies: the Multi-Ethnic Study of Atherosclerosis (MESA), which was conducted on different ethnicities, and the Whitehall II study, which found no significant association between MDS and incidence of type 2 
Table 2 Distribution of baseline characteristics and selected dietary factors according to the three categories of the Mediterranean diet scale (MDS)

\begin{tabular}{|c|c|c|c|c|c|c|c|}
\hline \multirow[t]{2}{*}{ Characteristic } & \multicolumn{6}{|c|}{ MDS score } & \multirow{2}{*}{$\begin{array}{c}\mathbf{P} \\
\text { for trend }\end{array}$} \\
\hline & \multicolumn{2}{|c|}{$\begin{array}{l}\text { Low } \\
(0-2)\end{array}$} & \multicolumn{2}{|c|}{$\begin{array}{c}\text { Moderate } \\
(3-4)\end{array}$} & \multicolumn{2}{|c|}{$\begin{array}{l}\text { High } \\
(5-8)\end{array}$} & \\
\hline Male (\%) & \multicolumn{2}{|c|}{45.6} & \multicolumn{2}{|c|}{42.3} & \multicolumn{2}{|c|}{41.2} & 0.489 \\
\hline \multirow[t]{2}{*}{ Family history of diabetes (\%) } & \multicolumn{2}{|c|}{50.0} & \multicolumn{2}{|c|}{40.0} & \multicolumn{2}{|c|}{38.4} & 0.933 \\
\hline & Mean & SD & Mean & SD & Mean & SD & \\
\hline Age (years) & 48.1 & 12.9 & 50.1 & 12.6 & 52.8 & 12.7 & 0.033 \\
\hline Body mass index $(\mathrm{kg} / \mathrm{m} 2)$ & 29.0 & 5.7 & 29.3 & $5 \cdot 3$ & 29.1 & 5.2 & 0.852 \\
\hline Waist circumference $(\mathrm{cm})$ & 96.5 & 14.0 & 97.3 & 11.7 & 96.3 & 12.5 & 0.856 \\
\hline Physical activity (MET/min/week) & 531 & 732 & 569 & 828 & 646 & 749 & 0.809 \\
\hline Total energy intake (kcal) & 1942 & 585 & 2165 & 709 & 2504 & 664 & $<0.0001$ \\
\hline Total fibre (g) & 30.3 & 13.8 & 41.7 & 27.8 & 55.0 & 23.1 & $<0.0001$ \\
\hline Glycaemic load & 129.0 & 44.1 & 151 & 60.5 & 179 & 62.9 & $<0.0001$ \\
\hline Whole grains (g) & 36.8 & 65.8 & 43.9 & 63.4 & 79.1 & 105.0 & $<0.0001$ \\
\hline Protein (\%) & 14.6 & 3.2 & 15.1 & 6.4 & 14.6 & 2.5 & 0.685 \\
\hline Carbohydrate (\% of energy) & 55.0 & 6.6 & 57.8 & 7.2 & 61.0 & 6.7 & $<0.0001$ \\
\hline Fat (\% of energy) & 32.8 & 6.3 & 30.7 & 7.0 & 28.5 & $5 \cdot 9$ & $<0.0001$ \\
\hline Saturated fatty acid (\% of energy) & 12.1 & 3.0 & 10.1 & 2.7 & 8.5 & 2.2 & $<0.0001$ \\
\hline Trans-fatty acid (\% of energy) & 0.7 & 0.6 & 0.8 & 0.7 & 0.7 & 0.6 & 0.887 \\
\hline Monounsaturated fatty acid (\% of energy) & 10.8 & 2.5 & 10.4 & 3.1 & 9.6 & 2.6 & 0.017 \\
\hline Polyunsaturated fatty acid (\% of energy) & 6.1 & 2.1 & 6.3 & 2.2 & 6.3 & 2.5 & 0.031 \\
\hline Olive oil (g/day) & 0.8 & 1.8 & 0.9 & 1.9 & 1.7 & 2.9 & 0.003 \\
\hline
\end{tabular}

= standard deviation; $M E T$ = metabolic equivalent task.

${ }^{a}$ Linear regression was used for continuous variables and logistic regression for categorical variables by assigning the median value for each category of MDS treated as a continuous variable

diabetes $(16,32)$. Similarly, in a previous study of the TLGS, no association was observed between MDS adherence and metabolic syndrome (33). Contrary to our findings, some prospective studies have documented inverse associations between Mediterranean dietary pattern and the incidence of type 2 diabetes $(4,10,14,15,17-19)$. MartinezGonzalez et al. reported an 83\% decrease in incidence of type 2 diabetes among a Spanish population with high adherence to Mediterranean diet, assessed by original MDS score (10). In other studies including the Health Professionals Follow-Up study (HPFS), the Nurses' Health Study II (NHS II), the European Prospective Investigation into Cancer and Nutrition (EPIC), and the Multi-Ethnic
Cohort (MEC) study, high adherence to Mediterranean diet assessed by a priori diet scores reduced the incidence of type 2 diabetes by $12-28 \%(4,15,19)$.Varying results can indicate that the Mediterranean diet may not have the same effect on different populations (20).

The controversial findings can largely be attributed to the region where the Mediterranean diet was scored and the type of score used. For instance, the association was stronger in countries such as Spain and Italy compared to others $(10,12)$. According to Hoffman and Gerber, the effect of each component of the Mediterranean diet score on health can differ in different populations

\begin{tabular}{|c|c|c|c|c|c|}
\hline \multirow[t]{3}{*}{ Model } & \multicolumn{5}{|c|}{ MDS score } \\
\hline & \multirow{2}{*}{$\begin{array}{c}\text { Low }(0-2) \\
(\mathbf{n}=90) \\
\text { OR }\end{array}$} & \multicolumn{2}{|c|}{$\begin{array}{l}\text { Moderate (3-4) } \\
\qquad(n=260)\end{array}$} & \multicolumn{2}{|c|}{$\begin{array}{l}\text { High }(5-8) \\
(n=211)\end{array}$} \\
\hline & & OR & $95 \% \mathrm{CI}$ & $\mathrm{OR}$ & $95 \% \mathrm{CI}$ \\
\hline Crude model & 1 (reference) & 0.82 & $0.49-1.38$ & 0.95 & $0.56-1.61$ \\
\hline Model 1 & 1 (reference) & 0.77 & $0.38-1.54$ & 0.87 & $0.43-1.75$ \\
\hline Model 2 & 1 (reference) & 0.79 & $0.38-1.65$ & 0.93 & $0.44-1.96$ \\
\hline
\end{tabular}

$\mathrm{OR}=$ odds ratio; $\mathrm{CI}$ = confidence interval.

Model 1: conditional analysis matched on age, sex, and date of data collection and controlled for family history of diabetes, body mass index, educational level, smoking status, physical activity, and total energy intake.

Model 2: multiple adjusted model, additionally adjusted for waist circumference, hypercholesterolaemia, and hypertension. 
(34) due to disparities between the Mediterranean and nonMediterranean countries in food availability, priority given to specific foods in each food group, and processing and preparation of foods all of which affect the overall health benefits of the Mediterranean diet in nonMediterranean countries (34). In addition, it seems that the protective effect of the Mediterranean diet against chronic diseases relates to dietary behaviours such as the order of meals, the time of eating each meal and the meal patterns or other potentially confounders such as genetics, sleeping and sunlight exposure $(34,35)$. On the other hand, most of the studies used a modified MDS instead of the original one $(4,12,14-16,32)$, which could result in differences in prediction of disease risk between studies.

One of the components of MDS known to be beneficial is cereal consumption, regardless of glycaemic load, amount of fibre or degree of processing. Both refined and unrefined cereals get positive points (36). According to Biesalski et al., high fibre dietary carbohydrates may lead to a lower risk for diabetes among a healthy population (37). Also, it has been shown that a diet with low glycaemic load and a high MDS can effectively reduce the incidence of type 2 diabetes whereas a high glycaemic load, high MDS diet showed no significant relationship with type 2 diabetes (17). Iranians have high intakes of grains as the main source of energy, but most grains are of the refined type (loaded with white rice and bread) (38), in the traditional Mediterranean diet, cereals were largely unrefined (11). Therefore cereal consumption, regardless of its quality (refined or unrefined) might be a factor in part for the lack of association between MDS and type 2 diabetes in our study.

Based on a review of data on dietary fat and diabetes, replacing SFA and TFA with unsaturated fatty acids (PUFA and/or MUFA) can enhance insulin sensitivity and is likely to protect against type 2 diabetes (39). This is in contrast with our findings where MUFA to SFA ratio was related to an increase in diabetes risk; this finding was not significant when we adjusted for confounding factors though. On the other hand, an outstanding feature of the original Mediterranean diet is the abundant use of olive oil, containing a high ratio of MUFA to SFA beside its antioxidant properties, which may play role in preventing chronic diseases (34). The mean total intake of olive oil in our sample (1.1 $\mathrm{g}$ in both sexes; data not shown) was much lower than the Greek sample (45.5 in men and 38.7 in women) in Trichopoulou's study (11).

According to Hoffman and Gerber (34) the main source of MUFA intake in non-Mediterranean populations is animal fat rather than olive oil. This was confirmed in our study where olive oil consumption rose across categories of MDS, whereas MUFA intake declined. So the ratio of MUFA to SFA is not that highly affected by olive oil in our population and thus cannot be a predictor of diabetes risk.
In all diets, there are particular issues that cannot be seen in any comparisons. For instance, in our population daily median intake of fish was lower than that in the Greek population for which the MDS was originally designed (7.08 vs $23.7 \mathrm{~g}$ /day for men; 6.37 vs 18.8 g/day for women) (11). Besides the difference in quantity of fish consumed, the quality varies a great deal since the different methods of cooking affect the fatty acid content and the types of fish consumed also differ in the Islamic Republic of Iran and the Mediterranean countries (34). Red wine is another feature of the Mediterranean diet (37). Moderate alcohol consumption is hypothesized to have an enhancing effect on insulin sensitivity and thus to reduce the risk of diabetes (9).

One of the limitations of our study is the small sample size and case-control rather than prospective design, which is prone to reverse causality; however the nested case-control design allowed us to use only new cases of diabetes that were not diabetic or even pre-diabetic in past surveys of the cohort, so the risk of reverse causality is minimized substantially. Second, our study tried to draw a Mediterranean dietary pattern from usual diets of the participants, which may have led to imprecision of defining the Mediterranean diet. Last, but not least, due to the small sample size, subgroup analyses were not possible in our study.

There were several strengths to our study. This was the first study investigating the association between the Mediterranean dietary pattern, assessed by an a priori method, and type 2 diabetes among the MENA population. Precise case selection and use of objectivelyidentified diabetes (not self-reported per se), and the highly standardized serum processing, anthropometric measurements, and covariate assessment are among the other strengths.

In conclusion, we found no inverse association between the Mediterranean dietary pattern measured by MDS and type 2 diabetes, in this healthy adult Iranian population sample. The Iranian dietary pattern does not correspond closely to the Mediterranean dietary pattern, which might be responsible for the lack of significant association. Further large scale, prospective studies, especially in Asian and Middle Eastern populations, with modifications in the scoring to become more compliant with usual diets of the population, are needed to investigate the applicability of the Mediterranean dietary pattern to type 2 diabetes prevention.

Funding: This study was funded by a grant from the Research Institute for Endocrine Sciences, Shadid Beheshti University of Medical Sciences, Tehran, Islamic Republic of Iran.

Competing interests: None declared. 


\section{Habitudes alimentaires méditerranéennes et risque de diabète de type 2 en Répu- blique islamique d'Iran}

\section{Résumé}

Contexte : Plus d'un pour cent ( $1 \%$ des Iraniens âgés de 20 ans et plus vivant en zones urbaines développent un diabète de type 2 chaque année. Le surpoids causé par le déséquilibre énergétique et l'alimentation de mauvaise qualité constitue l'un des principaux facteurs du diabète. Même s'il existe des rapports sur les effets bénéfiques de certains aliments isolés sur le métabolisme du glucose, les chercheurs se concentrent actuellement de plus en plus sur les habitudes alimentaires plutôt que sur la consommation d'aliments simples.

Objectif : L'objectif de la présente étude était d'évaluer l'association entre l'adhésion à un régime méditerranéen et le risque de développer un diabète de type 2 .

Méthodes : La présente étude est une étude cas-témoins nichée dans la cohorte de l'étude de Téhéran sur le glucose et les lipides. Parmi les participants qui répondaient aux critères de l'étude, 187 cas incidents de diabète ont été identifiés et appariés avec 374 témoins en bonne santé en fonction du sexe, de l'âge, de la date de la collecte des données et des précédentes interventions liées au mode de vie.

Résultats : La catégorie la plus élevée de l'échelle du régime méditerranéen était caractérisée par des apports en énergie, en fibres et en glucides élevés, un apport total en graisses élevé, une forte charge glycémique et une consommation importante d'huile d'olive, ainsi que par des apports en acides gras saturés et en acides gras monoinsaturés moins élevés. Les multiples odds ratio ajustés pour le diabète de type 2 chez les personnes présentant une adhésion moyenne (score 3-4) et élevée (score 5-8) à l'échelle du régime méditerranéen étaient de 0,79 (IC à 95\%:0,38-1,65) et 0,93 (IC à 95 \% :0,44-1,96), respectivement, comparativement aux personnes présentant une faible adhésion (score 0-3).

Conclusion : L'adhésion au régime alimentaire méditerranéen n'était pas associée au diabète de type 2. L'augmentation des taux de diabète de type 2 en République islamique d'Iran pourrait être imputable aux différences culturelles et traditionnelles entre les régimes alimentaires iranien et méditerranéen.

$$
\text { الأناط الغذائة في منطقة البحر المتوسط ومضان، كلانه أصغر الإصابة بالنمط الثاني من داء السكري في جمهورية إيران الإسالامية }
$$

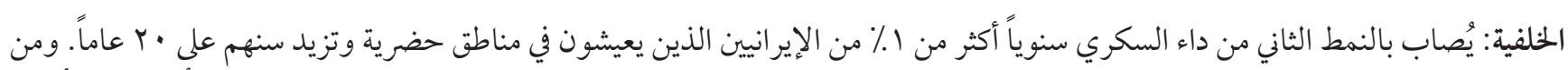

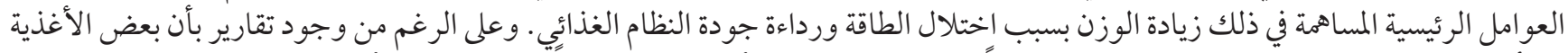

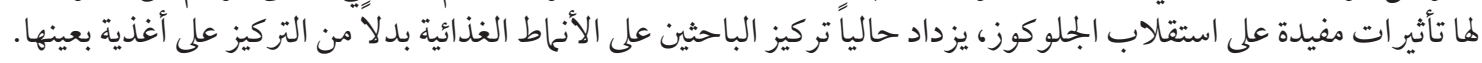
الأهداف: هدفت هذه الدراسة إلى تقييم العلاقة بين الالتز ام بنظام غذائي متوسطي وخطر الإصابة بالنمط الثاني من داء السكري.

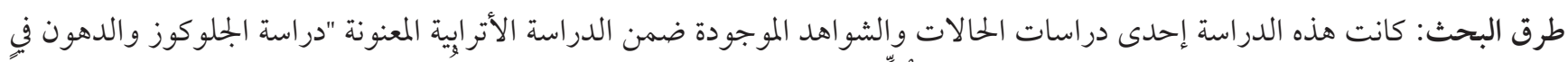

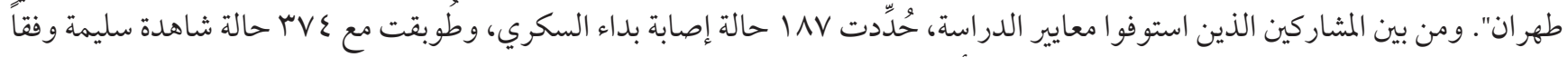

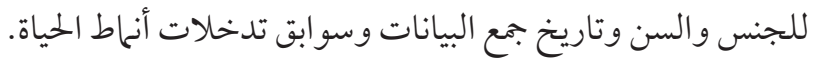

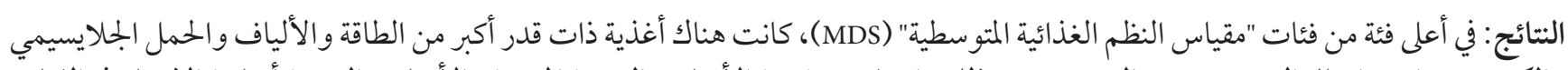

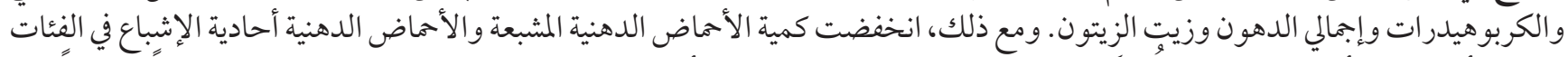

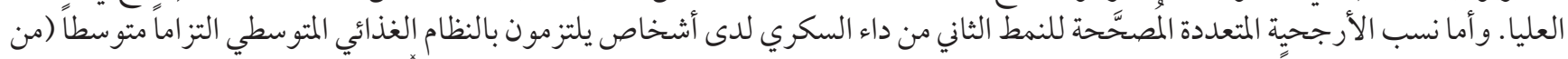

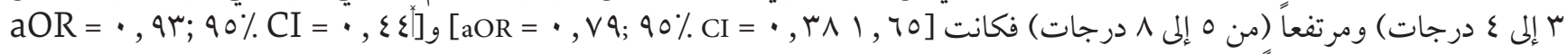

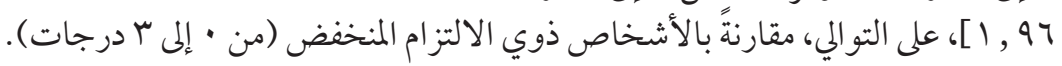

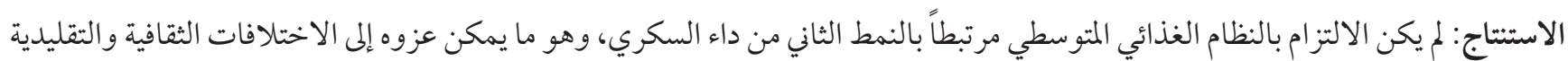
بين أنحاط الغذاء الإيرانية والمتوسطية. الإلنئ.

\section{References}

1. Wild S, Roglic G, Green A, Sicree R, King H. Global prevalence of diabetes: estimates for the year 2000 and projections for 2030. Diabetes Care. 2004;27(5):1047-53. PMID:15111519

2. Harati H, Hadaegh F, Saadat N, Azizi F. Population-based incidence of Type 2 diabetes and its associated risk factors: results from a six-year cohort study in Iran. BMC Public Health. 2009;9:186. doi:10.1186/1471-2458-9-186

3. American Diabetes Association. Diagnosis and classification of diabetes mellitus. Diabetes Care. 2014;37(Supplement 1):S81-90. doi:10.2337/dc14-So81 
4. de Koning L, Chiuve SE, Fung TT, Willett WC, Rimm EB, Hu FB. Diet-quality scores and the risk of type 2 diabetes in men. Diabetes Care. 2011;34(5):1150-6. doi:10.2337/dc10-2352

5. Panagiotakos DB, Tzima N, Pitsavos C, Chrysohoou C, Zampelas A, Toussoulis D, et al. The association between adherence to the Mediterranean diet and fasting indices of glucose homoeostasis: the ATTICA Study. J Am Coll Nutr. 2007;26(1):32-8. PMID:17353581

6. Bach-Faig A, Geleva D, Carrasco J, Ribas-Barba L, Serra-Majem L. Evaluating associations between Mediterranean diet adherence indexes and biomarkers of diet and disease. Public Health Nutr. 2006;9(8A):1110-7. doi:10.1017/S1368980007668499

7. Aljefree N, Ahmed F. Association between dietary pattern and risk of cardiovascular disease among adults in the Middle East and North Africa region: a systematic review. Food \& nutrition research. 2015;59:27486. doi: 10.3402/fnr.v59.27486

8. Perez-Jimenez F, Lopez-Miranda J, Mata P. Protective effect of dietary monounsaturated fat on arteriosclerosis: beyond cholesterol. Atherosclerosis. 2002;163(2):385-98. PMID:12052487

9. Schroder H. Protective mechanisms of the Mediterranean diet in obesity and type 2 diabetes. J Nutr Biochem. 2007;18(3):149-60. doi:10.1016/j.jnutbio.2006.05.006

10. Martinez-Gonzalez MA, de la Fuente-Arrillaga C, Nunez-Cordoba JM, Basterra-Gortari FJ, Beunza JJ, Vazquez Z, et al. Adherence to Mediterranean diet and risk of developing diabetes: prospective cohort study. BMJ. 2008;336(7657):1348-51. doi:10.1136/ bmj.39561.501007.BE

11. Trichopoulou A, Costacou T, Bamia C, Trichopoulos D. Adherence to a Mediterranean diet and survival in a Greek population. N Engl J Med. 2003;348(26):2599-608. doi:10.1191/1358863x04vm552xx

12. Mozaffarian D, Marfisi R, Levantesi G, Silletta MG, Tavazzi L, Tognoni G, et al. Incidence of new-onset diabetes and impaired fasting glucose in patients with recent myocardial infarction and the effect of clinical and lifestyle risk factors. Lancet. 2007;370(9588):667-75. doi:10.1016/S0140-6736(07)61343-9

13. Panagiotakos DB, Pitsavos C, Arvaniti F, Stefanadis C. Adherence to the Mediterranean food pattern predicts the prevalence of hypertension, hypercholesterolemia, diabetes and obesity, among healthy adults; the accuracy of the MedDietScore. Prev Med. 2007;44(4):335-40. doi:10.1016/j.ypmed.2006.12.009

14. Romaguera D, Guevara M, Norat T, Langenberg C, Forouhi NG, Sharp S, et al. Mediterranean diet and type 2 diabetes risk in the European Prospective Investigation into Cancer and Nutrition (EPIC) study: the InterAct project. Diabetes Care. 2011;34(9):19138. doi:10.2337/dc11-0891

15. Tobias DK, Hu FB, Chavarro J, Rosner B, Mozaffarian D, Zhang C. Healthful dietary patterns and type 2 diabetes mellitus risk among women with a history of gestational diabetes mellitus. Arch Intern Med. 2012;172(20):1566-72. doi:10.2337/dc11-0891

16. Abiemo EE, Alonso A, Nettleton JA, Steffen LM, Bertoni AG, Jain A, et al. Relationships of the Mediterranean dietary pattern with insulin resistance and diabetes incidence in the Multi-Ethnic Study of Atherosclerosis (MESA). Br J Nutr. 2013;109(8):1490-7. doi:10.1017/Sooo7114512003339

17. Rossi M, Turati F, Lagiou P, Trichopoulos D, Augustin LS, La Vecchia C, et al. Mediterranean diet and glycaemic load in relation to incidence of type 2 diabetes: results from the Greek cohort of the population-based European Prospective Investigation into Cancer and Nutrition (EPIC). Diabetologia. 2013;56(11):2405-13. doi:10.1007/s00125-013-3013-y

18. Salas-Salvado J, Bullo M, Estruch R, Ros E, Covas MI, Ibarrola-Jurado N, et al. Prevention of diabetes with Mediterranean diets: a subgroup analysis of a randomized trial. Ann Intern Med. 2014;160(1):1-10. doi:10.7326/M13-1725

19. Jacobs S, Harmon BE, Boushey CJ, Morimoto Y, Wilkens LR, Le Marchand L, et al. A priori-defined diet quality indexes and risk of type 2 diabetes: the Multiethnic Cohort. Diabetologia. 2015;58(1):98-112. doi:10.1007/s00125-014-3404-8

20. Schwingshackl L, Missbach B, Konig J, Hoffmann G. Adherence to a Mediterranean diet and risk of diabetes: a systematic review and meta-analysis. Public Health Nutr. 2015;18(7):1292-9. doi:10.1017/S1368980014001542

21. Azizi F, Ghanbarian A, Momenan AA, Hadaegh F, Mirmiran P, Hedayati M, et al. Prevention of non-communicable disease in a population in nutrition transition: Tehran Lipid and Glucose Study, phase II. Trials. 2009;10:5. doi:10.1186/1745-6215-10-5

22. Asghari G, Rezazadeh A, Hosseini-Esfahani F, Mehrabi Y, Mirmiran P, Azizi F. Reliability, comparative validity and stability of dietary patterns derived from an FFQ in the Tehran Lipid and Glucose Study. Br J Nutr. 2012;108(6):1109-17.

23. Mirmiran P, Esfahani FH, Mehrabi Y, Hedayati M, Azizi F. Reliability and relative validity of an FFQ for nutrients in the Tehran lipid and glucose study. Public Health Nutr. 2010;13(5):654-62.

24. Hosseini-Esfahani F, Asghari G, Mirmiran P, Jalali Farahani S, Azizi F. Reproducibility and relative validity of food group intake in a food frequency questionnaire developed for the Tehran Lipid and Glucose Study. Razi J Med Sci. 2010;17(71):41-55.

25. Azar M, Sarkisian E. Food composition table of Iran. Islamic Republic of Iran: Institute of Nutrition Sciences and Food Technology, 1980.

26. Azar M, Sarkisian E. Food composition table of Iran. In: Editor Report No: 131. Tehran: Institute of Nutrition Sciences and Food Technology; 1980.

27. Atkinson FS, Foster-Powell K, Brand-Miller JC. International tables of glycemic index and glycemic load values: 2008. Diabetes Care. 2008;31(12):2281-3. PMID:18835944

28. Momenan AA, Delshad M, Sarbazi N, Rezaei Ghaleh N, Ghanbarian A, Azizi F. Reliability and validity of the Modifiable Activity Questionnaire (MAQ) in an Iranian urban adult population. Arch Iran Med. 2012;15(5):279-82. doi:012155/AIM.oo7. 
29. James PA, Oparil S, Carter BL, Cushman WC, Dennison-Himmelfarb C, Handler J, et al. 2014 evidence-based guideline for the management of high blood pressure in adults: report from the panel members appointed to the Eighth Joint National Committee (JNC 8). JAMA. 2014;311(5):507-20. doi:10.1001/jama.2013.284427

30. Grundy SM. United States cholesterol guidelines 2001: expanded scope of intensive low-density lipoprotein-lowering therapy. American J Cardiol. 2001;88(7):23-7. PMID:11595195

31. Willett WC, Howe GR, Kushi LH. Adjustment for total energy intake in epidemiologic studies. American J Clinical Nutrition. 1997;65(4):1220S-8S. doi:10.1093/ajcn/65.4.1220S

32. Brunner EJ, Mosdol A, Witte DR, Martikainen P, Stafford M, Shipley MJ, et al. Dietary patterns and 15-y risks of major coronary events, diabetes, and mortality. Am J Clin Nutr. 2008;87(5):1414-21. doi:10.1093/ajcn/87.5.1414

33. Mirmiran P, Moslehi N, Mahmoudof H, Sadeghi M, Azizi F. A longitudinal study of adherence to the Mediterranean dietary pattern and metabolic syndrome in a non-Mediterranean population. Int J Endocrinol Metab. 2015 Jul 1;13(3):e26128. doi:10.5812/ ijem.26128v2

34. Hoffman R, Gerber M. Evaluating and adapting the Mediterranean diet for non-Mediterranean populations: a critical appraisal. Nutr Rev. 2013;71(9):573-84. doi:10.1111/nure.12040

35. Sanchez-Villegas A, Martinez JA, De Irala J, Martinez-Gonzalez M Determinants of the adherence to an "a priori" defined Mediterranean dietary pattern. Eur J Nutr. 2002;41(6):249-57. doi:10.1007/s00394-002-0382-2

36. Dominguez LJ, Bes-Rastrollo M, de la Fuente-Arrillaga C, Toledo E, Beunza JJ, Barbagallo M, et al. Similar prediction of total mortality, diabetes incidence and cardiovascular events using relative- and absolute-component Mediterranean diet score: the SUN cohort. Nutr Metab Cardiovasc Dis. 2013 May;23(5):451-8. doi:10.1016/j.

37. Biesalski HK. Diabetes preventive components in the Mediterranean diet. Eur J Nutr. 2004;43(Suppl. 1):I/26-30. doi:10.1007/ s00394-004-1106-6

38. Esmaillzadeh A, Azadbakht L. Major dietary patterns in relation to general obesity and central adiposity among Iranian women. J Nutr. 2008;138(2):358-63. PMID:18203904

39. Brehm BJ, Lattin BL, Summer SS, Boback JA, Gilchrist GM, Jandacek RJ, et al. One-year comparison of a high-monounsaturated fat diet with a high-carbohydrate diet in type 2 diabetes. Diabetes Care. 2009;32(2):215-20. doi:10.2337/dc08-0687 